\title{
ESPAÇO PÚBLICO DE LAZER - PROJETO URBANÍSTICO PARA O BALNEÁRIO MUNICIPAL DE PAULICÉIA / SP
}

Luana Akinaga Marotti; Yeda Ruiz Maria.

Universidade do Oeste Paulista - UNOESTE, Curso de Arquitetura e Urbanismo, Presidente Prudente, SP. Email: lumarotti.vest@hotmail.com.

\section{RESUMO}

O presente trabalho apresentará breves definições que englobam os conceitos de espaço público, lazer e turismo e a relação com a área em estudo. Tendo como objetivo a compreensão do local, através dos usos atuais, pontuando suas carências e potencialidades, levantando as atividades de lazer já existentes na cidade e no Balneário Municipal de Paulicéia - SP, para agregar maior valor ao espaço. Assim, o estudo se deu por meio da pesquisa bibliográfica, análises do objeto de estudo e seu entorno, através de fotos e visitas in loco. Resultando na observação de que há carência de espaços públicos de lazer na cidade e o Balneário sendo o principal meio de suprir essas necessidades. Portanto, o espaço de estudo em questão, se encontra subutilizado pela falta de infraestrutura e variedade de usos, que permita que o local se torne o principal meio de lazer para a população e turistas da cidade.

Palavras-chave: Balneário; lazer; espaço; público; turismo.

\section{PUBLIC SPACE OF RECREATION - URBAN PROJECT FOR THE MUNICIPAL BALNEARY OF PAULICÉIA / SP}

\begin{abstract}
This paper will present brief definitions that encompass the concepts of public space, leisure and tourism and the relationship with the area under study. Aiming at understanding the place, through current uses, punctuating its needs and potential, raising the existing leisure activities in the city and the Municipal Balneary of Paulicéia - SP, to add greater value to the space. Thus, the study was carried out through bibliographic research, analyzes of the object of study and its surroundings, through photos and visits in loco. Resulting in the observation that there is a lack of public spaces of leisure in the city and the Balneary is the main means to meet these needs. Therefore, the study space in question is underutilized by the lack of infrastructure and variety of uses, which allows the place to become the main means of leisure for the population and tourists of the city.
\end{abstract}

Keywords: Balneary; recreation; space; public; turism. 


\section{INTRODUÇÃO}

O espaço público é um local aberto por natureza, com função primordial que facilita seu acesso pelas pessoas, portanto é um local onde todos os indivíduos podem utilizar com os mesmos direitos.

[...] os atributos de um espaço público são aqueles que têm relação com a vida pública [...] E, para que esse 'lugar' opere em uma atividade pública, é necessário que se estabeleça, em primeiro lugar, uma copresença de indivíduos (GOMES apud ALEX, S., p. 19, 2011).

Assim, os espaços públicos são elementos essenciais e decisivos no desenho urbano, pois é neles em que se há a manifestação da vida urbana e onde acontece grande parte da socialização dos usuários. Portanto, eles constituem elementos estruturantes da vida urbana, visto que, ao estimular o desenvolvimento urbano, contribuem para a valorização da qualidade de vida e vivência urbana (MATOS, 2010).

Os espaços públicos, principalmente os de lazer, são um dos aspectos indispensáveis para a revitalização e a qualidade de vida no meio urbano. O lazer é algo que deve satisfazer as necessidades do indivíduo, sobretudo as necessidades sociais e de descanso. Está relacionado à qualidade de vida, pois as pessoas estão trabalhando cada vez mais e passam os dias em meio ao trânsito e agitação do dia a dia. Para fugir desta realidade, a população busca locais para descansar e fugir da rotina (MANOLESCU; SANTOS, 2008).

As manifestações do lazer contribuem para o turismo, ou seja, o turismo em si se concretiza através do tempo livre do indivíduo, no qual ele pode utilizá-lo para a prática do lazer. Portanto, o turismo se dá como o deslocamento temporário de pessoas para outros locais visando à satisfação de necessidades que não sejam remuneradas. Por assim dizer, o seu conceito geral se liga diretamente ao lazer, contemplando aspectos importantes quanto às relações sociais e modos de vida (HIGUCHI; RIBEIRO, 2008).

Nesse sentido, o presente artigo trata do Balneário Municipal de Paulicéia SP, um espaço público de lazer já existente na cidade com subutilização, pois há a falta de infraestrutura que atenda as demandas do local o tornando pouco atrativo à população usuária, assim seu uso é dado por um número muito inferior em relação a sua real capacidade.

O objetivo deste estudo foi compreender os usos atuais do local, pontuando suas carências e potencialidades e levantar as atividades de lazer existentes na cidade e no Balneário, afim de agregar valor ao local.

\section{METODOLOGIA}

O conjunto de métodos adotados teve uma visão de modo a diagnosticar e orientar melhorias no desempenho funcional, construtivo e paisagístico da área do Balneário Municipal de Paulicéia - SP. Foi utilizado de pesquisas em campo com auxílio de fotografias e com relação à parte de pesquisa, foram adotados estudos bibliográficos através de teses, artigos e livros.

\section{RESULTADOS}

A cidade de Paulicéia - SP, possui uma grande carência de equipamentos públicos de lazer voltados para sua população, sendo existentes duas grandes praças e uma delas possuindo um pequeno playground e uma academia para terceira idade. Além disso, possui um centro comunitário, que funciona apenas quando possui alguma festividade, um campo de futebol e o Balneário Municipal de Paulicéia - SP. 
Já o entorno próximo do Balneário Municipal de Paulicéia - SP se faz majoritariamente pela presença de áreas verdes, com as Áreas de Preservação Permanente (APP), que margeiam os cursos d'água presentes, o Rio Paraná e o Córrego Itaí, que são protegidas por lei, margeadas pelos condomínios residenciais, pelas áreas de cultivo de cana-de-açúcar e a produção de gado (Figura 1).

Figura 1. Mapa de localização do Balneário Municipal de Paulicéia - SP e seu entorno mais próximo.

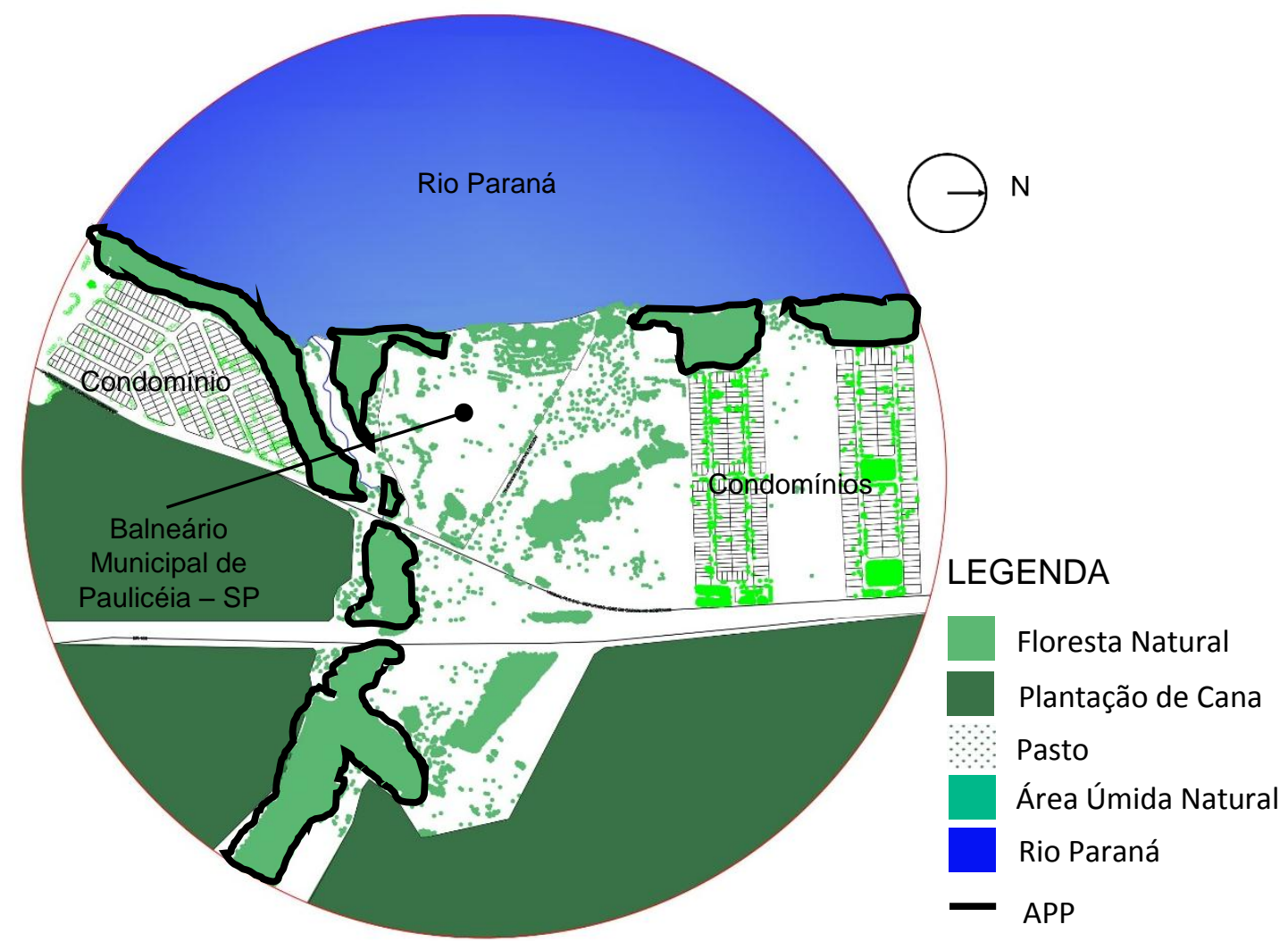

Fonte: Prefeitura Municipal de Paulicéia - SP, com alterações da autora com auxílio dos dados do Mapa Biomas, 2017.

A partir dos estudos feitos no Balneário, foi possível destacar seus principais usos existentes, como a utilização da área para banho, quiosques e área aberta com churrasqueiras (Figura 2), quiosques comerciais para refeição, uma pista de motocross para a realização da competição que ocorre no período de carnaval, além de uma área de estacionamento. 
Figura 2. Área com churrasqueiras e área de banho.

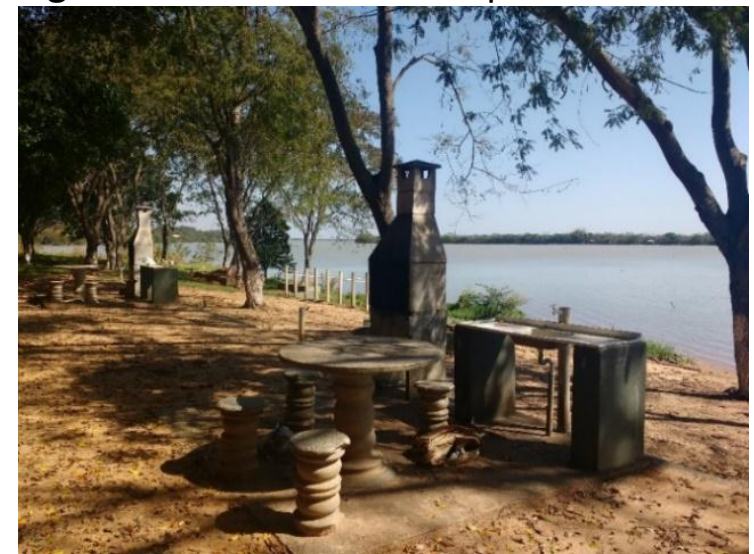

Fonte: Autora, 2018.

A partir destes levantamentos, pode-se observar a carência de espaços públicos de lazer na cidade de Paulicéia - SP e o Balneário Municipal como o principal meio de suprir essa necessidade, através de seu espaço com uma grande potencialidade, além de sua extensa área localizada às margens do Rio Paraná.

Ressaltando-se que o local já é estabelecido como uma área de lazer na cidade e seu uso é enraizado pela população local, porém seus usos são inferiores a sua real capacidade, pois local se encontra sem manutenção e com infraestrutura precária.

\section{DISCUSSÃO}

O entorno do Balneário Municipal de Paulicéia - SP é dado pelo predomínio de condomínios fechados que evidenciam a fragmentação e segregação urbana que ocorre na cidade, sendo que nestes locais não há interação social ou vida urbana, pois houve a redução do espaço público e natural, este que deveria ser acessível a todos, resultando em um esvaziamento significativo da vida urbana, pois não existe coletividade, convívio ou socialização. Este comprometimento da acessibilidade, acaba tornando o espaço um local de passagem, sem a vivência urbana.

Há ainda a presença de áreas verdes, compostas por APP's e áreas de pastagem, além do cultivo da cana-de-açúcar. Já a área do Balneário é caracterizada por um local de lazer, sendo que estes usos trazem influências diretas ao espaço público, como os condomínios fechados, que com seus muros voltados para as ruas bloqueiam uma das suas principais características que é o de conectar as pessoas com o espaço. Sendo que este problema se agrava por se localizar em uma via de pouca movimentação de pedestres e sem iluminação, assim o espaço não possibilita o uso noturno, pois o mesmo provoca uma rejeição imediata pela população.

A arborização do local de estudo e do seu entorno é um ponto muito importante, pois se encontram grandes massas verdes, as APP's que são formações vegetais associadas aos cursos d'água presentes no local, estão que estão ligadas diretamente ao conforto ambiental e o controle de ruídos, pois se tornam barreiras naturais, além de serem, essencialmente, corredores biológicos.

O Balneário Municipal possui fluxos no interior em função da área de banho ou para a área onde acontecem as competições esportivas de motocross (Figura 3). Na área de banho este fluxo se dá de maneira livre, porém seu caminho possui problemas quanto à acessibilidade, sendo um local de lazer público, fica implícito que o lugar deveria ter livre acesso a todos os tipos de pessoas, o que pode-se observar que isto não acontece no local, 
contendo escadarias que levam à área de banho e algumas rampas que não atendem à norma NBR 9050 (2015) de acessibilidade à locais públicos.

Figura 3. Área de estudo, sem escala.

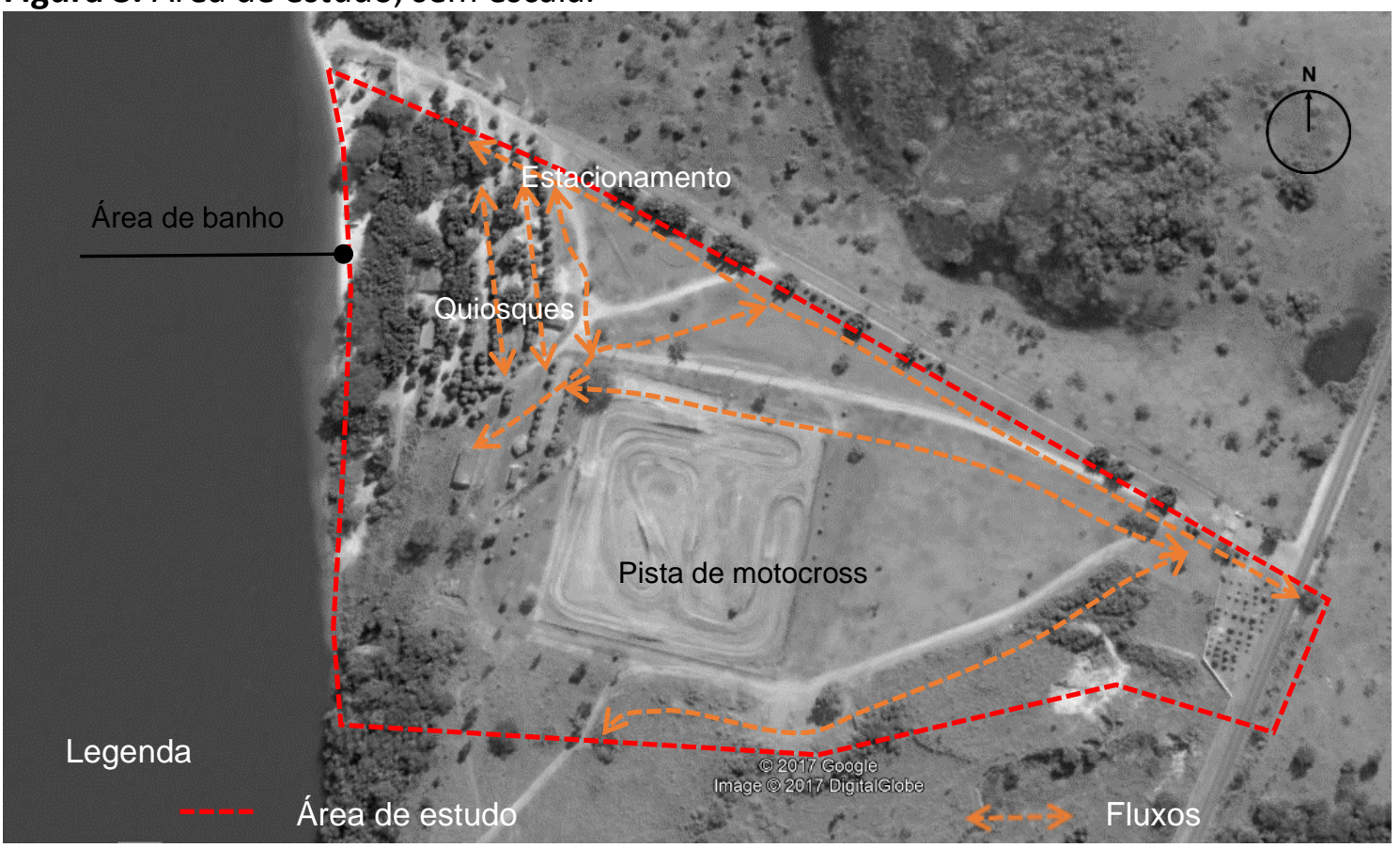

Fonte: Google Earth 2017, com alterações da autora, 2018.

Seu uso se intensifica aos finais de semana e principalmente durante os feriados, onde a população local a utiliza como espaço de lazer com a família e amigos. Durante o carnaval, há eventos esportivos desenvolvidos em uma área específica do Balneário Municipal, que é o motocross, que atrai pessoas de diversos locais para acompanhar a competição.

Por fim pode se destacar que o Balneário Municipal de Paulicéia - SP é o principal meio de lazer para a população pauliceiense, porém se encontra em condições precárias pela sua falta de manutenção. Sendo assim, seu uso acaba sendo inferior a sua real potencialidade, que pode atrair moradores da região e turistas locais, além de ser um importante meio de educação ecológica para a população, através da possibilidade de contato direto com a natureza.

O local ainda proporciona um maior bem estar e melhoria na qualidade de vida das pessoas e possui uma grande capacidade de influir no uso familiar, promovendo encontros e trocas pessoais.

\section{CONCLUSÃO}

A cidade de Paulicéia - SP, possuindo uma grande carência de equipamentos públicos de lazer tendo como o Balneário uma opção de grande importância para suprir estas necessidades, local este que já possui uso fundado pela sua população que o frequenta periodicamente, se fazendo muito importante na região, porém o mesmo se encontra subutilizado, pela falta de infraestrutura que permita que o espaço se torne o principal meio de lazer para a população e turistas da cidade, devido a sua potencialidade.

Conclui-se com este trabalho, que o local ao manter o uso do espaço como um local de lazer, ampliando seus usos, ou seja, potencializando o espaço, tornando-o mais 
atrativo juntamente com a implantação de ações ambientais, fará com que seus usuários se identifiquem e apropriem do Balneário no seu dia-a-dia, trazendo maior vitalidade, incentivando a união do meio ambiente com o homem, dando para seus usuários uma nova visão do área.

\section{REFERÊNCIAS}

ABNT, Associação Brasileira de Normas Técnicas. ABNT NBR 9050: Acessibilidade a edificações, mobiliário, espaços e equipamentos urbanos. 3. ed. Rio de Janeiro: ABNT, 2015. ALEX, Sun. Projeto da praça: convívio e exclusão no espaço público. 2. ed. São Paulo: Senac São Paulo, 2011.

HIGUCHI, Maria I. G.; RIBEIRO, Maria de N. Lima. Percepções sobre turismo, lazer e conservação ambiental: um estudo com moradores do entorno de uma reserva florestal urbana. Turismo em análise, v. 19, n. 3, dez. 2008.

IBGE Cidades. Paulicéia - SP. Acessado em 2017. Disponível em <https://biblioteca.ibge.gov.br/visualizacao/dtbs/saopaulo/pauliceia.pdf>.

MATOS, Fátima Loureiro de. Espaços públicos e qualidade de vida nas cidades: o caso da cidade Porto. Revista eletrônica de geografia, v. 2, n. 4, p. 17-33, jul. 2010.

MANOLESCU, Friedhilde M. K.; SANTOS, Ana Carolina M. F. dos. A importância do espaço para o lazer em uma cidade. XII Encontro Latino Americano de Iniciação Científica e VIII Encontro Latino Americano de Pós-Graduação, Universidade do Vale do Paraíba, 2008. 